\section{[-2]pro-Prostataspezifisches Antigen}

\section{S. Holdenrieder}

Institut für Laboratoriumsmedizin, Deutsches Herzzentrum München, Klinik an der Technischen Universität München, München, Deutschland

\section{Synonym(e) [-2]proPSA}

Definition [-2]proPSA ist wie das [-4], [-5] und [-7]proPSA eine Vorläuferform des PSA. In Tumorextrakten wurde v. a. die [-2]proPSA-Form gefunden, die auch mittels eines Immunoassays im Serum detektiert werden kann. In einer prospektiven Studie zeigte sich der Quotient von [-2]proPSA zu freiem PSA (\%[-2]proPSA) bei der Diagnose des Prostatakarzinoms dem Gesamt-PSA ( $\triangleright$ Prostataspezifisches Antigen) im PSA-Bereich $2-10 \mathrm{ng} / \mathrm{mL}$ überlegen. Ein multivariates Modell, welches das Gesamt-PSA, \%fPSA und \%[-2] proPSA einschließt, erzielte eine weitere Steigerung der diagnostischen Trennscharfe im PSA-Bereich 2-10 ng/mL. Diese gelang ebenso durch die Kombination von \%[-2]proPSA und
PSA im sogenannten $>$ Prostate Health Index (PHI), wodurch insbesondere die Spezifität der Prostatakarzinomdiagnostik erhöht wurde. In einer multivariaten Studie wurde die Überlegenheit von \%[-2]proPSA und PHI gegenüber Gesamt-PSA und \%fPSA zur Detektion eines Prostatakarzinoms im Bereich $2-10 \mathrm{ng} / \mathrm{ml}$ PSA bei der initialen und wiederholten Biopsie bestätigt. Somit eignen sich sowohl \%[-2]proPSA wie auch PHI zur Patientenberatung vor einer Biopsie.

\section{Literatur}

Boegemann $\mathrm{M}$ et al (2016) The percentage of prostate-specific antigen (PSA) isoform [-2]proPSA and the Prostate Health Index improve the diagnostic accuracy for clinically relevant prostate cancer at initial and repeat biopsy compared with total PSA and percentage free PSA in men aged $\leq 65$ years. BJU Int 117:72-79

Jansen FH et al (2010) Prostate-specific antigen (PSA) isoform p2PSA in combination with total PSA and free PSA improves diagnostic accuracy in prostate cancer detection. Eur Urol 57:921-927

Sokoll LJ et al (2010) A prospective, multicenter, National Cancer Institute Early Detection Research Network study of [-2]proPSA: improving prostate cancer detection and correlating with cancer aggressiveness. Cancer Epidemiol Biomark Prev 19:1193-1200 